\title{
The Challenges and Selection of Comparative Education Research under the Era of New Media
}

\author{
Yan Xia ${ }^{1, a}$ \\ ${ }^{1}$ Jiangxi Science \&Technology Normal University, Nanchang, Jiangxi, 330000 \\ a email
}

Keywords: New Media Era, Comparative Education Review, Challenges and Choices

\begin{abstract}
With the deepening of the reform era of new media, in a significant widening of comparative education research team to enhance the research subject; but gradually due to cultural homogenization and similar enhancements, resulting in education comparability between various countries also present gradually improve. Comparative Education Research With the expansion of space-time, comprehensive research methods evolved. With the advent of the new media age, more education, while access to development opportunities is also facing a huge challenge, which only carry out continuous reform and innovation to further enhance their own development and prosperity. By analyzing the challenges the Institute of Comparative Education in the New Era of media, and discuss its future development options and directions on this basis, we hope to be able to compare the current education research and development to bring some help and impetus.
\end{abstract}

\section{Introduction}

With the advent of rapid development of society and the new media age, the traditional gradually become an important factor in the current social stability and development. Internet as the main representative of the new media, technological change, global media ecology caused a great degree of change, promote the traditional mode of information production and dissemination suffered from changes in nature and, thus, promote the people's life and production methods have gradually shift . It can be said that this new media technology will have a significant impact on the overall social change, let people come into the community to have a higher level of information civilization. In this era of new media background, Comparative Education Research with the overall change of society will inevitably suffer a new challenge,

\section{Compare Challenge Institute of Education in the New Media Age}

The moment, many of the traditional limitations and boundaries are suffering from digestion of digital technology, such as border and other traditional television, radio and the communication between the media being phased out digestion; boundaries between and within countries, between the community and the industry has gradually is dispelled; the boundary between the sender and receiver of information is gradually digested [1]. No matter how new media will gradually begin to merge between interpersonal and mass media, and the formation of a new media forms. Digestion phenomenon of new media era, so in terms of a certain perspective, but also in the traditional culture to break the monopoly, to promote culture in the face of increasingly diversified, Mass. This is a full range of digestion, not only to the traditional boundaries between media out to digestion, but also to promote geographical boundaries and cultures gradually been weakened to some extent. However, this digestion also brought a certain extent, simply, is to make leading position suffered the impact of traditional culture. In the current era of universal information network background, everyone is under the master network information, equality and the bright main rings, discourse dominance comparative education research is also being suffered many aspects of supervision and questioned. According to the 2008 survey showed that the number of Internet users in the world has grown to number about 1.5 billion, which accounted for nearly $22 \%$ of the proportion of the world's total population of about 6.7 billion, but also increasing year by year. Under this background, 
comparative education research discourse dominance will gradually decline, but the research team will also gradually expand, and gradually move closer to mass, and gradually buy grass-roots.

Comparative Education Research the most common method is to compare, it is comparisons between different national education systems, concepts and methods, so that the localization of educational wisdom and resources gradually formed and produced. Today's society, some people believe that comparative education has gradually developed into a comprehensive research, including comparative education, international education, foreign education and the development of education [2]. Comparability from the traditional sense, represents the similarity, this has a very significant show in comparison subjects. However, comparability in the comparison subjects has gradually crossed the similar appearance, which pay more attention to the study of the existence of each other the nature of contact, simply, it is required to have a certain degree of homogeneity. With the new media era of blurring boundaries and gradually increase cultural homogeneity, but also enhance the cultural similarities between some extent, and thus comparability bring a certain impetus. With the advent of the new media age, it is more education studies, to some extent, the expansion of education comparability between countries, enrich the content of international education comparison, generalization phenomenon gradually formed.

\section{Choose Direction Comparative Education Research in the New Media Age}

Because every nation and there are different historical periods and geographical environment, which prompted them to their respective phenomena of nature and society have a different understanding and awareness and, thus, created culture with its own characteristics. Each national education system in the relevant programs or standards, are often firmly rooted in their system itself, and is closely linked to its symbiotic conditions, and these conditions into another country will want to exist many difficulties difficult to achieve. Real and effective for all outstanding education, they are derived from various national life and character control. It is in the nation's long history of latent suitable for their own needs [3]. Therefore, the basic characteristics of education is to nationality, there is a lack of lack of nationality worldwide. In the current era of new media, along with the increasing homogenization of culture and how cultural uniqueness and to reinforce the independence of the focus at the moment is similar cultural background. Therefore, regardless of the manner in which the similarity of education in enhancing or reinforcing the extent to which, in the field of vision comparable level of cultural diversity and to respect individuality, to return to education on the basis of localization, has been relatively Institute for Education and certainly insist on the concept of discipline. And we can only richer in education on the basis of personality, to compare heavy marching to international education.

Tickets into the world is culture. Comparison of education tend to be more understanding, but also a way to understand the culture carried out. New media technology innovation reform also to some extent the style of human existence, people's living space is no longer a "trinity" of physical space, but gradually to "all media" space forward [4]. Many forms of so-called all-media, simply, is by means of text, graphics, electricity, etc., to show the full range of communication content, and the help of various means of communication to spread the new form for transmission. Comparative Education Research in the new media age capable of forming a new perspective, not only study the body and consciousness is gradually spreading and promotion, accompanied constantly enhance the comparability and the broader field of study, and bring research new experience. These conditions will also support the Comparative Education Research gradually towards prosperity, bringing to power their development. Diversification of education by means of constantly adjusting international relations and nationalization, so to establish a new world culture system more quickly, thus contributing to the development of cultural pluralism has been effectively promoted. The means of transmission and maintenance of international cultures, will also bring complementarity between the various national culture help promote greater [5]. By strengthening the different international cultural communication, we will contribute to mutual understanding between the various national culture, to promote racial and cultural prejudice and so can be reduced and eliminated. These no doubt will actively promote the development of cultural diversity. With 
Comparative Education Research rising, destined to education in a more pluralistic culture, we continue to optimize and improve the localization of education and culture.

\section{Conclusion}

In sum, although Comparative Education Research in the New Media Age background will face many challenges, but at the same time, also brought new opportunities for the development of their discipline to some extent. Therefore, only the Subject Orientation of the Comparative Education Research in the new media era background, methodology and problem areas on issues such as ongoing research and analysis in order to make more rapid pace of development of comparative education.

\section{References}

[1] Jiang Zhaowen. From "Comparative Education Research" Situation Analysis of Research Papers Comparative Education [J]. Comparative Education Research, 2014,02: 12-17.

[2] Zhang Haichuan. Challenges and Countermeasures new media era ideological and political education work faces [J]. Inner Mongolia Normal University (Education Science Edition), 2014, 09: 53-55.

[3] Dou Libo, Bi Jiarong. Analysis Challenges and Strategies of Ideological and Political Education in the New Media Era [J]. Education Forum, 2015, 09: 49-50.

[4] Chen Jin, Chen Wenjie. Opportunities and challenges of the new media age mental health education faces [J]. Education Article (on Xunkan), 2009, 07: 75-76.

[5] Li Tao, Xi Jianping, Dong Jianping. Challenge all media era Cadets Ideological and Political Education and Countermeasures [J]. Military Jiaotong University, 2014,06: 72-76. 